\title{
Erratum to: An alternate protocol for establishment of primary caprine fetal myoblast cell culture: an in vitro model for muscle growth study
}

\author{
Satyendra Pal Singh • Rohit Kumar • Priya Kumari • \\ Abhijit Mitra
}

Published online: 3 July 2013

(C) The Society for In Vitro Biology 2013

\section{Erratum to: In Vitro Cell.Dev.Biol.-Animal}

DOI 10.1007/s11626-013-9642-0

In the Discussion section, second to the last paragraph, third sentence from the end, "MSTN" was inadvertently written with a wrong acronym "MRFs". As a result, the sentence should have read "In comparison to fibroblasts, we also observed lower abundance of transcripts of MSTN in all the myogenic cell types" rather than "transcripts of MRFs" as published. All other sentences in the article are correct.

The online version of the original article can be found at http://dx.doi.org/ 10.1007/s11626-013-9642-0.

R. Kumar P. Kumari $\cdot$ A. Mitra $(\bowtie)$

Genome Analysis Laboratory, Animal Genetics Division, Indian Veterinary Research Institute, Izatnagar 243122, India

e-mail: drabhijitmitra@gmail.com

Present Address:

S. P. Singh

Department of Animal Genetics and Breeding, C.o.V.Sc. \& A.H.,

DUVASU, Mathura 281001, India 